\title{
Lipid profile as a predictor of Neuropathy: The Sheffield Prospective Diabetes Study.
}

\author{
Satyan Rajbhandari ${ }^{1,2}$, Fahad Syed Hamid ${ }^{2}$, Nigel Harris ${ }^{1}$, Solomon Tesfaye ${ }^{1}$ \\ ${ }^{1}$ Diabetes Research Unit, Royal Hallamshire Hospital, Sheffield, ${ }^{2}$ Lancashire Teaching Hospital, Preston \\ Road, Chorley
}

\begin{abstract}
Background : Despite being a very common complication, the aetiology and potential risk factors of diabetic neuropathy (DN) have not been clearly determined in a prospective study. Aims: The aim of Sheffield Prospective Diabetes Study was to identify the abnormalities of physiological, biochemical, haemorrhelogical and cellular function for complications of diabetes in type 1 diabetes.

Materials and Methods: 66 newly diagnosed type 1 diabetic subjects (mean age 31 9(SD) duration (3 years \pm 2 ) were identified and followed for 9 years. They had detailed neurological assessment (symptoms and signs score, nerve conduction, vibration perception threshold, warm thermal discrimination threshold and autonomic function tests) and blood samples taken for detail biochemical and haemorrheological analysis at base line and at follow up.

Results: At the 9 years follow up, 51 subjects were studied of whom 18 were found to have DN using Dyck's criteria. As expected subjects with DN had significantly higher $(\mathrm{p}<0.01)$ mean HbA1 over 9 years of follow up (11.8\% vs $9.8 \%)$, but it was not significantly different at base line $(10.2 \% \mathrm{vs} 8.9 \%$; $\mathrm{p}=0.37$ ). In addition, total cholesterol and LDL cholesterol at baseline were found to be risk factors for the development of neuropathy ( $5.9 \mathrm{vs} 4.7 \mathrm{mmol}$; $\mathrm{p}=0.01$ and $3.7 \mathrm{vs} 2.8 \mathrm{mmol}$; $=0.03$ respectively).

Conclusions: This prospective study confirms the findings of recent large epidemiological studies linking cardiovascular risk factors to the development of DN, and perhaps suggest a vascular aetiology for DN. Improvement of potentially modifiable risk factors for neuropathy may be useful for the development of risk reduction strategies.
\end{abstract}

Key Words: LDL - Low Density Lipoprotein, HDL - High density lipoprotein, DN - Diabetic Neuropathy, NN - Non- neuropath subjects, SD - Standard deviation

\section{Introduction:}

The pathogenic mechanism leading to Diabetic neuropathy (DN) in human is not fully understood. Animal studies have established the presence of a number of metabolic abnormalities such as oxidative stress, sorbitol accumulation, PKC activation, accumulation of advanced glycated products in DN. ${ }^{4}$ Similarly vascular abnormalities

Corresponding Author: Professor Satyan M Rajbhandari, Consultant Physician, Lancashire Teaching Hospital, Honorary Clinical Professor, University of Central Lancashire, Chorley \& South Ribble Hospital, Preston Road, Chorley PR7 1PP, UK Tel (44) 1257 245028, Email:Satyan.rajbhandari@lthtr.nhs.uk such as endoneurial and epineurial vessels changes, nerve hypoxia etc have also been demonstrated. ${ }^{8}$ Similar findings have also been demonstrated in human DN. ${ }^{9}$

Epidemiological and prospective studies have identified hypertension ${ }^{6}$, increasing age, duration of diabetes and poor glycaemic control ${ }^{1}$ as a significant risk factor for the development of DN. There has been association between lipids and $\mathrm{DN}$ but there is still a paucity of well-conducted prospective study in this field. 
Sheffield Prospective diabetes study was started with the aim of identifying risk factors associated with the development of diabetic complications in type 1 subjects. This study was approved and funded by Diabetes UK.

\section{Methods:}

In this prospective observational study, sixty-six (25 Females) newly diagnosed Type 1 diabetes subjects (mean age 31 - 9(SD) duration (3 years -2) were recruited from a busy diabetes clinic. All consecutive patients who were diagnosed with type 1 diabetes within the last 5 years were approached when they came to the diabetes clinic. Subjects were deemed to have type 1 diabetes if the age at diagnosis was less than 40 and needed insulin within six months of diagnosis. Only those subjects who agreed for detailed neurophysiological examination and long term follow up were included in the study. Subjects who were likely to leave the area, such as university students were excluded. They had clinical neurological assessment performed by neurological symptoms questionnaire and neurological examination. Nerve conduction velocity of median motor, median sensory, peroneal motor and sural sensory nerves was measured at 22 0C using Dantac 2000. ${ }^{13}$ For qualitative sensory tests, vibration perception threshold over the great toe was measured using neurothesiometer and warm thermal detection threshold over the dorsum of right foot using thermo-aesthesiometer. Cardiac autonomic function tests were performed using O'Brien protocol. They also had fasting lipid profiles (serum cholesterol, fasting triglycerides, HDL cholesterol and LDL cholesterol) and HbA1c measured. The overall diabetes control (mean $\mathrm{HbA} 1$ ) was measured from the laboratory database by calculating the mean of all $\mathrm{HbA} 1$ performed over the study period.

They were treated in diabetes clinic as any other patients without any active intervention. At 9 years they were again invited for detailed follow up as above. Only 51 subjects (77\%) attended for follow up as 15 patients had moved out of the area or refused to attend for detailed neurophysiologication (Figure 1). Diagnosis of diabetic neuropathy was made using Dyck's criteria (Dyck 1988).

\section{Results:}

At baseline visit $14(21.2 \%)$ out of 66 subjects had evidence of neuropathy on detailed neurophysiological examination. Out of 52 subjects without neuropathy $(\mathrm{NN})$ at baseline, 42 were followed up and 9 subjects (21.4\%) developed new onset DN. At 9 years visit 33 subjects $(64.7 \%)$ did not have neuropathy $(\mathrm{NN})$ and 18 subjects $(35.3 \%)$, 9 new and 9 established subjects, had DN.

When the lipid levels of 18 subjects with DN was compared with 33 subjects without neuropathy, the levels were raised in all visits (table 1). As expected the overall control over 9 years was poor in DN subjects (mean HbA1 $11.8+/-2.1 \%$ vs 9.8 +/$1.9 \% ; \mathrm{p}<0.01)$ however this was not statistically significant on the first visit $(10.2+/-3.2 \%$ vs 8.9 $+/-3.0 \% ; \mathrm{p}=0.37$ ).

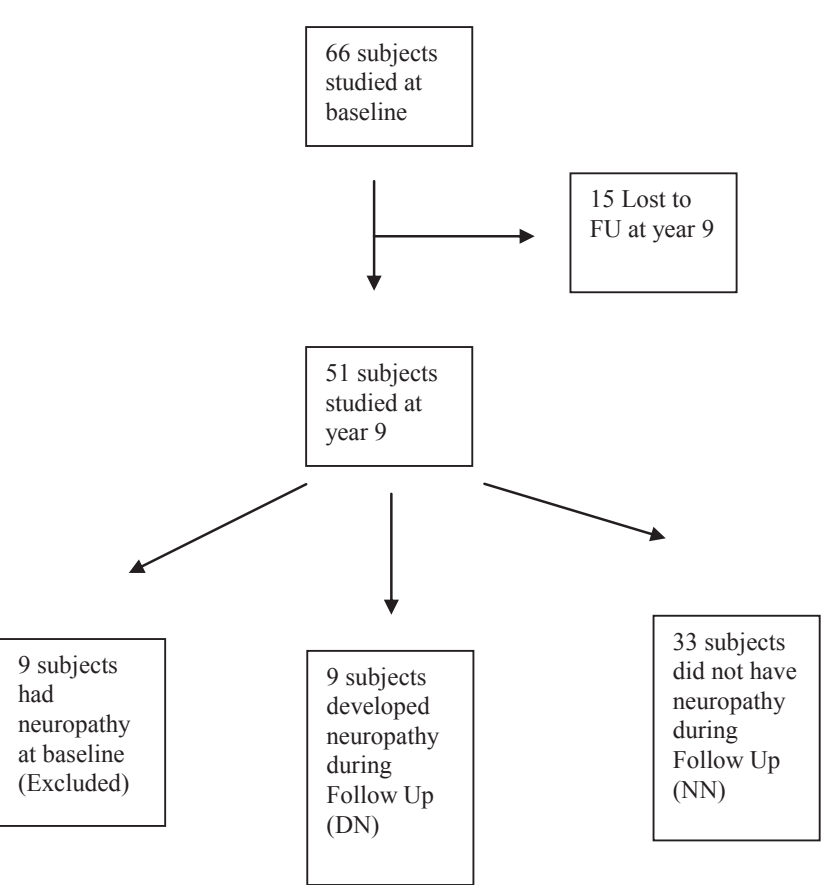

Figure 1: Flowchart of study 
Table 1: Lipid profile of subjects who have diabetic neuropathy at 9 years follow up in comparison to subjects who did not have neuropathy.

\begin{tabular}{|c|c|c|c|c|c|c|}
\hline & \multicolumn{2}{|c|}{ Non-Neuropath } & \multicolumn{2}{|c|}{ Diabetic Neuropathy } & \multirow[b]{2}{*}{$p$ Value } \\
\hline & & Mean & SD & Mean & SD & \\
\hline \multirow[t]{2}{*}{ Triglyceride } & Initial Visit & 1.30 & 1.38 & 1.63 & 0.84 & 0.03 \\
\hline & Final Visit & 1.06 & 0.45 & 1.89 & 1.44 & 0.05 \\
\hline \multirow[t]{2}{*}{ Cholesterol } & Initial Visit & 4.73 & 1.12 & 5.57 & 1.18 & 0.02 \\
\hline & Final Visit & 4.99 & 0.81 & 5.76 & 1.08 & 0.02 \\
\hline \multirow{2}{*}{$\begin{array}{l}\mathrm{HDL} \\
\text { Cholesterol }\end{array}$} & Initial Visit & 1.36 & 0.34 & 1.29 & 0.47 & 0.34 \\
\hline & Final Visit & 1.33 & 0.35 & 1.34 & 0.46 & 0.84 \\
\hline \multirow{2}{*}{$\begin{array}{l}\text { HDL / Total } \\
\text { cholesterol } \\
\text { Ratio }\end{array}$} & Initial Visit & 3.67 & 1.40 & 4.71 & 1.53 & 0.0 \\
\hline & Final Visit & 3.97 & 1.25 & 4.69 & 1.53 & 0.12 \\
\hline \multirow{2}{*}{$\begin{array}{l}\text { LDL } \\
\text { Cholesterol }\end{array}$} & Initial Visit & 2.83 & 1.08 & 3.55 & 1.06 & 0.02 \\
\hline & Final Visit & 3.22 & 0.89 & 3.57 & 0.83 & 0.24 \\
\hline
\end{tabular}

Nine subjects who were NN at first visit developed DN during follow up. In order to look into risk factors for the development of DN, the baseline lipid profiles of these subjects were compared with $33 \mathrm{NN}$ subjects. We found that total cholesterol and LDL cholesterol was significantly raised in this group at baseline with a trend for elevated triglyceride and HDL / Total cholesterol ratio (table 2). There were no significant differences in the overall diabetes control at baseline between these groups $(11.1+/-4.3 \% \mathrm{vs} 8.9+/-3.0 \%$; $\mathrm{p}=0.15)$, however during follow up, the 9 year's mean $\mathrm{HbA} 1$, was raised $(12.0+/-2.3 \%$ vs $9.8+/-1.9 \%$; $\mathrm{p}=0.01$ ). The baseline lipid profiles of subjects lost to follow up was statistically no different to those followed up for 9 years.

Table 2: Baseline lipid profiles of subjects who developed new onset diabetic neuropathy during follow up in comparison to those subjects without diabetic neuropathy

\begin{tabular}{|c|c|c|c|c|c|}
\hline & \multicolumn{2}{|c|}{ Non - Neuropathy } & \multicolumn{2}{|c|}{$\begin{array}{l}\text { New Diabetic } \\
\text { neuropathy }\end{array}$} & \multirow[b]{2}{*}{$p$ Value } \\
\hline & Mean & SD & Mean & SD & \\
\hline Triglyceride & 1.30 & 1.38 & 1.69 & 0.91 & 0.08 \\
\hline Cholesterol & 4.73 & 1.12 & 5.88 & 1.06 & 0.01 \\
\hline $\begin{array}{l}\mathrm{HDL} \\
\text { Cholesterol }\end{array}$ & 1.36 & 0.34 & 1.42 & 0.55 & 0.78 \\
\hline $\begin{array}{l}\text { HDL / Total } \\
\text { Cholesterol } \\
\text { Ratio }\end{array}$ & 3.67 & 1.40 & 4.59 & 1.47 & 0.06 \\
\hline \begin{tabular}{|l|} 
LDL \\
Cholesterol
\end{tabular} & 2.83 & 1.08 & 3.70 & 0.97 & 0.03 \\
\hline
\end{tabular}




\section{Discussion:}

Previous studies have shown association of lipids to DN. In Eurodiab study Tesfaye et $a{ }^{19}$ have shown baseline triglycerides to be associated with neuropathy and have shown both triglycerides and cholesterol to be a risk factor for the development of DN. ${ }^{5}$ On the other hand Spallone et al ${ }^{17}$ did not find any relation between autonomic neuropathy and lipids. Similarly Maser et al ${ }^{14}$ did not find any relation between lipids and vibration threshold. In a recent epidemiological study in young people with diabetes, risk factors for neuropathy in Type $1 \mathrm{DM}$ were older age, longer diabetes duration, smoking, increased diastolic blood pressure, obesity, increased LDL cholesterol and triglycerides, and lower HDL cholesterol. In youth with Type 2 $\mathrm{DM}$, risk factors were older age, male sex, longer diabetes duration, smoking, and lower HDL-c. ${ }^{11}$ Our study shows that at baseline both total cholesterol and LDL cholesterol is significantly elevated in subjects who later developed DN. Both total cholesterol and fasting triglycerides levels were significantly raised in subjects with Diabetic neuropathy. Microvascular abnormalities is thought to be the aetiology of neuronal damage. ${ }^{18}$ It is possible that similar to hypertension, lipids also contribute to both macrovascular and microvascular complications. The elevated lipids may be in part responsible for reported raised mortality in diabetic neuropathy. ${ }^{7}$

The HbA1 was not statistically different between these two groups at base line, although the mean $\mathrm{HbA} 1$ was higher in subjects who later developed DN. The overall control of diabetes was poor in DN group during the 9 year follow up. We did not find any difference between the HDL levels in these two groups. This may be due to both male and female subjects being pooled together. HDL is higher in female subjects. We did not analyse the data separately as the numbers were smaller.

Elevated lipids have been associated with other microvascular complications of diabetes. Triglycerides has been shown to be a risk factor for the development of proliferative diabetic retinopathy. ${ }^{2}$ In subjects with diabetic nephropathy, Zimmermann et $\mathrm{al}^{20}$ demonstrated significantly higher concentrations of LDLcholesterol, triglycerides and lower concentrations of HDL-cholesterol. In diabetic nephropathy deterioration of renal function has been retarded by LDL plasma apheresis. ${ }^{16}$ Similarly HMG Co A reductase inhibitors have been shown to reduce the deterioration in renal function in experimental diabetic nephropathy ${ }^{10,12}$, however, the mechanism is thought to be independent of its lipid lowering effect. Therapy with a statin or a fibrate was shown to have protective effect against the development of diabetic peripheral sensory neuropathy ${ }^{3,15}$

\section{Conclusion:}

This prospective study confirms the findings of recent large epidemiological studies linking cardiovascular risk factors to the development of DN, and perhaps suggest a vascular aetiology for DN. Improvement of potentially modifiable risk factors for neuropathy may be useful for the development of risk reduction strategies.

\section{REFERENCE:}

1. Adler AI. Boyko EJ. Ahroni JH. Stensel V. Forsberg RC. Smith DG. Risk factors for diabetic peripheral sensory neuropathy. Results of the Seattle Prospective Diabetic Foot Study. Diabetes Care. 20(7):1162-7, 1997 Jul

2. Davis MD, Fisher MR, Gangnon RE, Barton F, Aiello LM, Chew EY, Ferris FL 3rd, Knatterud GL. Risk factors for high-risk proliferative diabetic retinopathy and severe visual loss: Early Treatment Diabetic Retinopathy Study Report :18. Investigative Ophthalmology \& Visual Science. 39(2):233-52, 1998 Feb.

3. Davis TM, Yeap BB, Davis WA, Bruce DG. Lipid-lowering therapy and peripheral sensory neuropathy in type 2 diabetes: the Fremantle Diabetes Study. Diabetologia. 2008 Apr;51(4):562-6.

4. Dyck PJ. Detection, characterization, and staging of polyneuropathy: assessed in 
diabetics. [Review] [38 refs] Muscle \& Nerve. 11(1):21-32, 1988 Jan.

5. Tesfaye S, Chaturvedi N, Eaton SE et al (2005) Vascular risk factors and diabetic neuropathy. NEJM 352: 341- 50

6. Forrest KY. Maser RE. Pambianco G. Becker DJ. Orchard TJ. Hypertension as a risk factor for diabetic neuropathy: a prospective study. Diabetes. 46(4):665-70, 1997 Apr.

7. Forsblom CM. Sane T. Groop PH. Totterman KJ. Kallio M. Saloranta C. Laasonen L. Summanen P. Lepantalo M. Laatikainen L. Matikainen E. Teppo AM. Koskimies S. Groop L. Risk factors for mortality in Type II (noninsulin-dependent) diabetes: evidence of a role for neuropathy and a protective effect of HLADR4. Diabetologia. 41(11):1253-62, 1998 Nov.

8. Greene DA. Arezzo JC. Brown MB. Effect of aldose reductase inhibition on nerve conduction and morphometry in diabetic neuropathy. Zenarestat Study Group. Neurology. 53(3):58091, 1999 Aug 11.

9. Ibrahim S. Harris ND. Radatz M. Selmi F. Rajbhandari S. Brady L. Jakubowski J. Ward JD. A new minimally invasive technique to show nerve ischaemia in diabetic neuropathy. Diabetologia. 42(6):737-42, 1999 Jun.

10. Inman SR. Stowe NT. Cressman MD. Brouhard BH. Nally JV Jr. Satoh S. Satodate R. Vidt DG. Lovastatin preserves renal function in experimental diabetes. American Journal of the Medical Sciences. 317(4):215-21, 1999 Apr.

11. Jaiswal M, Divers J, Dana Dabelea, Scott Isom, Ronny A. Bell, Catherine L. Martin, David J. Pettitt, Sharon Saydah, Catherine Pihoker, Debra A. Standiford, Lawrence M. Dolan, Santica Marcovina, Barbara Linder, Angela D. Liese, Rodica Pop-Busui and Eva L. Feldman. Prevalence of and Risk Factors for Diabetic Peripheral Neuropathy in Youth With Type 1 and Type 2 Diabetes: SEARCH for Diabetes in Youth Study. Diabetes Care 2017 Sep; 40(9): 1226-1232.

12. Jandeleit-Dahm K. Cao Z. Cox AJ. Kelly DJ. Gilbert RE. Cooper ME. Role of hyperlipidemia in progressive renal disease: focus on diabetic nephropathy. [Review] [27 refs] Kidney
International - Supplement. 71:S31-6, 1999 Jul. 13. Malik RA. Tesfaye S. Thompson SD. Veves A. Hunter A. Sharma AK. Ward JD. Boulton AJ. Transperineurial capillary abnormalities in the sural nerve of patients with diabetic neuropathy. Microvascular Research. 48(2):236-45, 1994 Sep.

14. Maser RE, Usher DC, DeCherney GS. Little association of lipid parameters and large sensory nerve fiber function in diabetes mellitus. Journal of Diabetes \& its Complications. 10(1):54-9, 1996 Jan-Feb.

15. Nagamatsu M. Nickander KK. Schmelzer JD. Raya A. Wittrock DA. Tritschler H. Low PA. Lipoic acid improves nerve blood flow, reduces oxidative stress, and improves distal nerve conduction in experimental diabetic neuropathy. Diabetes Care. 18(8):1160-7, 1995 Aug.

16. Nakao T. Yoshino M. Matsumoto H. Okada T. Han M. Hidaka H. Shino T. Yamada C. Nagaoka Y. Miyahara T. Low-density lipoprotein apheresis retards the progression of hyperlipidemic overt diabetic nephropathy. Kidney International - Supplement. 71:S206-9, 1999 Jul.

17. Spallone V, Maiello MR, Cicconetti E, Menzinger G. Autonomic neuropathy and cardiovascular risk factors in insulin-dependent and non insulin-dependent diabetes. Diabetes Research \& Clinical Practice. 34(3):169-79, 1997 Jan.

18. Tesfaye S. Malik R. Ward JD. Vascular factors in diabetic neuropathy. Diabetologia. 37(9):847-54, 1994 Sep.

19. Tesfaye S, Stevens LK, Stephenson JM, Fuller $\mathrm{JH}$, Plater M, Ionescu-Tirgoviste C, Nuber A, Pozza G, Ward JD. Prevalence of diabetic peripheral neuropathy and its relation to glycaemic control and potential risk factors: the EURODIAB IDDM Complications Study. Diabetologia. 39(11):1377-84, 1996 Nov.

20. Zimmermann J. Schramm L. Mulzer E. Heidbreder E. Henrich HA. Wanner C. Cardiovascular risk factors in diabetic nephropathy. Medizinische Klinik. 92(2):74-8, 1997 Feb 15. 